\title{
Preparação, Caracterização e Aplicação de Membranas Anisotrópicas de Poliacrilonitrila
}

\author{
Rodrigo C. Lavall, Maria Elizabeth F. Garcia e Ronaldo Nobrega
}

Resumo: A pervaporação, que é um dos processos com membranas empregado em separações seletivas específicas, como misturas azeotrópicas, misturas diluídas e misturas orgânicas, tem despertado um grande interesse nos últimos anos. Neste trabalho foram estudadas a influência de parâmetros, tais como concentração da solução polimérica, tempo de exposição, concentração de aditivo e temperatura de tratamento térmico na preparação de membranas assimétricas de poliacrilonitrila. Em função destes parâmetros, as membranas foram observadas por microscopia eletrônica de varredura (MEV), e determinada a cinética de precipitação em experimentos de transmissão de luz. Os resultados mostram que a precipitação é instantânea. As membranas compostas de poliacrilonitrila, obtidas pelo espalhamento de uma solução diluída de poli(álcool vinílico) sobre as membranas assimétricas de poliacrilonitrila, foram caracterizadas na separação de misturas de água/etanol por pervaporação. Os resultados foram comparados com a membrana comercial da GFT de poli(álcool vinílico)/poliacrilonitrila.

Palavras-chave: Poliacrilonitrila, membranas anisotrópicas, membranas compostas, poli(álcool vinílico), pervaporação.

\section{Introdução}

$\mathrm{Na}$ indústria química, os processos de separação por membranas representam uma nova classe de operação unitária, e dentre eles, a pervaporação compete com processos clássicos de separação de misturas líquidas em condições específicas, como é o caso da quebra de azeótropos e o fracionamento de misturas diluídas ${ }^{[1]}$. Na pervaporação, a alimentação formada de dois ou mais componentes é circulada em contato com a membrana, e o permeado, na forma de vapor, é removido continuamente por intermédio de uma bomba de vácuo, ou uma corrente de gás inerte. O transporte das moléculas através da membrana densa se dá pelo mecanismo de sorção-difusão, e geralmente o componente que tem maior afinidade pelo polímero é o que permeia preferencialmente, e portanto é enriquecido no permeado ${ }^{[2,3]}$.

Dentre as diversas aplicações tecnológicas da pervaporação destaca-se a purificação de etanol, como um complemento da destilação, ou seja, na desidratação da mistura azeotrópica de etanol/água. Neste sentido, a membrana composta da GFT, que consiste de uma camada densa de poli(álcool vinílico) - PVA reticulado, depositada sobre uma membrana porosa de poliacrilonitrila - $\mathrm{PAN}^{[4]}$, tem sido empre-

Rodrigo C. Lavall, Escola de Química/UFRJ; Maria Elizabeth F. Garcia e Ronaldo Nobrega Laboratório de Processos de Separação por Membranas, PEQ/COPPE/UFRJ, Centro de Tecnologia, Bloco G, Sala 115, C.E.P: 21945-970, Cidade Universitária, llha do Fundão, Rio de Janeiro, RJ, E-mail: megarcia@peq.coppe.ufr.br 
gada comercialmente na desidratação desta mistura. Visando o desenvolvimento de membranas compostas de poliacrilonitrila para separação de misturas aquosas/orgânicas por pervaporação, este trabalho tem por objetivo estudar os parâmetros que afetam a preparação de membranas anisotrópicas de poliacrilonitrila, que servirão de suporte na obtenção de membranas compostas de PVA/PAN.

\section{Experimental}

\section{Preparação de membranas assimétricas de poliacrilonitrila}

As membranas foram obtidas a partir do espalhamento de uma solução do polímero em Nmetil-2-pirrolidona (NMP) sobre placas de vidro, seguido da imersão em um banho de não solvente (água). Em algumas soluções poliméricas empregouse um aditivo polimérico [poli(vinil-pirrolidona), peso molecular 360.000]. Na Tabela 1 estão listadas as concentrações das soluções utilizadas. As membranas obtidas a partir do sistema ternário [PAN/NMP/ ÁGUA] foram então tratadas termicamente,em água, a $90^{\circ} \mathrm{C}$, por um período de dez minutos, e colocadas em banhos de etanol e n-hexano, sequencialmente. As membranas obtidas a partir do sistema quaternário [PAN/PVP/NMP/ÁGUA] foram deixadas em estufa a $60^{\circ} \mathrm{C}$ por $12 \mathrm{~h}$, antes de serem colocadas em banho de etanol e n-hexano.

\section{Preparação de membranas compostas de poliacrilonitrila e poli(álcool vinílico)}

As membranas compostas foram obtidas pelo cobrimento da superfície da membrana de PAN, com uma solução diluída de PVA, para constituição da pele densa. A solução diluída a $3 \%$ em água do polímero foi refluxada a $90^{\circ} \mathrm{C}$, seguido da adição do agente de reticulação. Após devidamente

Tabela 1. Concentrações das soluções de poliacrilonitrila

\begin{tabular}{cccc}
\hline Soluções & $\begin{array}{c}\text { Concentração } \\
\text { PAN/NMP } \\
(\% \mathbf{\%} / \mathbf{p})\end{array}$ & Soluções & $\begin{array}{c}\text { Concentração } \\
\text { PAN/PVP/NMP } \\
(\% \mathbf{\%} / \mathbf{p})\end{array}$ \\
\hline I & $8 / 92$ & V & $12,5 / 6,25 / 81,25$ \\
II & $10 / 90$ & VI & $10 / 5 / 85$ \\
III & $12,5 / 87,5$ & VII & $10 / 10 / 80$ \\
IV & $15 / 85$ & VIII & $8 / 8 / 84$ \\
\hline
\end{tabular}

cobertas e secas, as membranas foram submetidas à reticulação em estufa a $100^{\circ} \mathrm{C}$ por 1 hora. Foi utilizado o ácido maleico como agente de reticulação, na concentração de $0,5 \%$ em relação ao mero de PVA, promovendo ligações cruzadas nas cadeias de PVA.

\section{Caracterização das membranas}

As membranas foram caracterizadas quanto a morfologia em um microscopio eletrônico de varredura (MEV), modelo Jeol 5300. A cinética de precipitação foi determinada a partir de medidas de transmissão de luz na solução polimérica, espalhada sobre placa de vidro e imersa em um banho de não-solvente. A precipitação das soluções foi acompanhada através da queda da transmitância, utilizando-se o equipamento apresentado na Figura 1a, que consiste de uma fonte de luz (lâmpada 60W) e um sensor fotoelétrico conectado a um computador, onde é feita a aquisição de dados ${ }^{[5]}$.

\section{Testes de Pervaporação}

As membranas preparadas com o procedimento descrito no ítem 1.2 foram avaliadas quanto ao desempenho na separação de misturas água/etanol por pervaporação. O sistema de pervaporação, ilustrado na Figura 1b, consiste de uma célula em aço inox provida de dois compartimentos, separados pela membrana. No compartimento superior circula a mistura de alimentação de concentração conhecida, em contato com a membrana. O compartimento inferior é mantido à pressão reduzida, com o auxílio de uma bomba de vácuo. O permeado é recolhido em cristalizadores, resfriados externamente por nitrogênio líquido. Os cristalizadores estão ligados à grade de vidro, situada na saída do compartimento inferior da célula de permeação.

O fluxo permeado, J, da membrana é obtido a partir do permeado coletado, através da equação, onde m é a massa do permeado, medida pela diferença de pesos do cristalizador antes e depois da corrida; $\mathrm{t}$ o tempo de corrida e $\mathrm{A}$ a área de permeação. A partir das concentrações da alimentação e permeado é determinada a seletividade da membrana, definida pelo fator de separação a: 

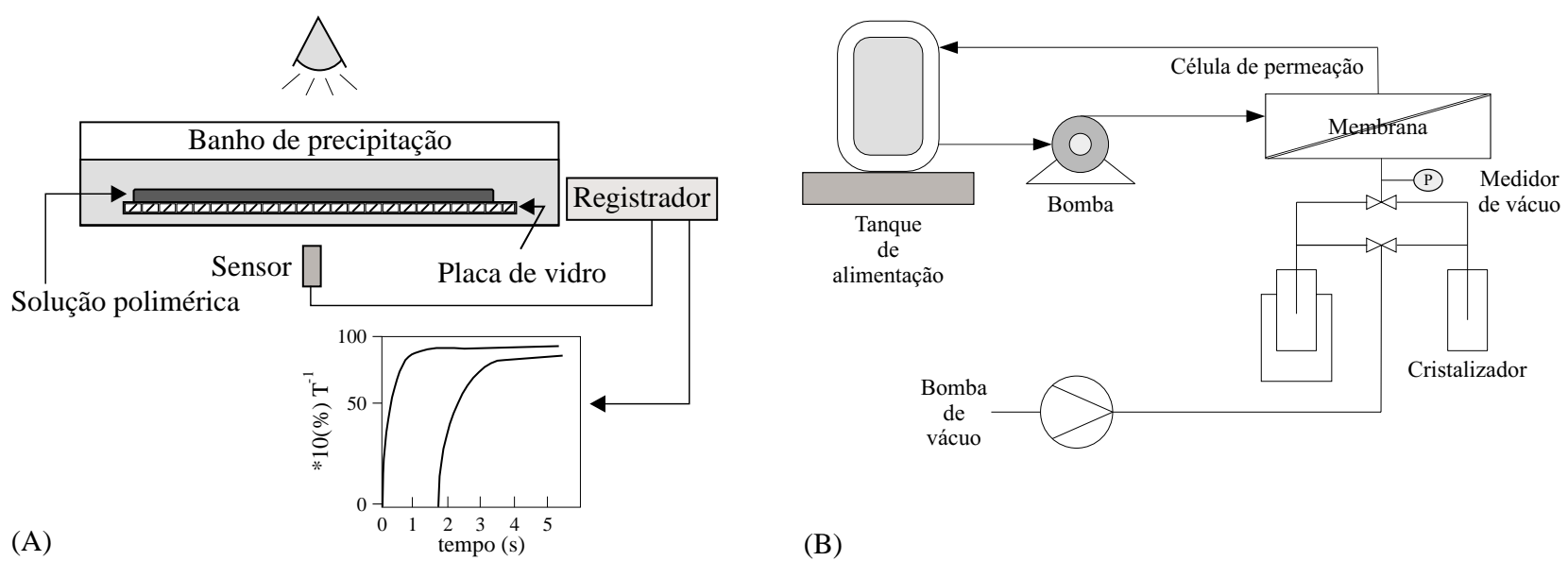

Figura 1. Esquema dos sistemas utilizados (A) acompanhamento da cinética de precipitação e (B) pervaporação.

$$
\alpha_{1,2}=\frac{Y_{1} / Y_{2}}{X_{1} / X_{2}}
$$

onde: $\mathrm{Y}$ - fração em peso do permeado; $\mathrm{X}$ - fração em peso da alimentação; 1 - componente que permeia preferencialmente

\section{Resultados e Discussão}

Dentre os parâmetros que podem afetar a morfologia e as propriedades de transporte de membranas anisotrópicas de poliacrilonitrila, selecionou-se a concentração da solução polimérica, a concentração de aditivo polimérico e o tratamento térmico da membrana, para serem apresentados neste trabalho.

\section{Efeito da concentração da solução polimérica}

A Figura 2 mostra que, a precipitação da membrana é decorrente do aumento na concentração de polímero na superfície da membrana, devido à gran-

(a)

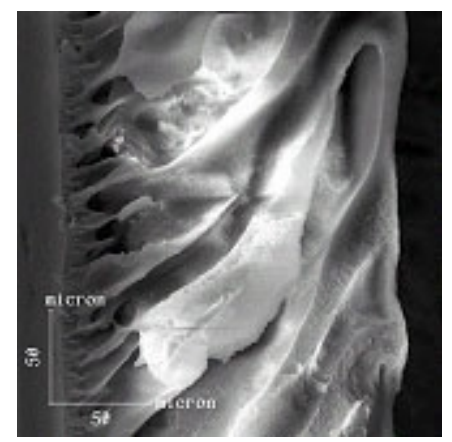

de diferença de potencial químico do solvente entre a solução polimérica e o banho de coagulação. Esta camada precipitada torna-se uma resistência adicional à transferência de massa nas subcamadas da solução, permanecendo estável por um tempo maior. Os primeiros núcleos formados, na camada logo abaixo da interface precipitada, crescem às custas do solvente da solução circundante, dando origem aos macroporos. Estes macroporos aparecem desarrumados, mas tendem a se alinhar com o aumento da concentração de polímero.

Para os sistemas ternários estudados também foram realizados ensaios de transmissão de luz durante a precipitação, para as diferentes concentrações de solução polimérica. A Figura 3 mostra as curvas referentes à queda da transmitância de luz através do filme de solução polimérica imerso no banho de não solvente, com tempo de leitura dos dados de 50 min. Observa-se que o aumento da concentração de polímero é acompanhado por um pequeno decréscimo na velocidade de precipitação, confirmando a hipótese de que o aumento de concentração de polímero provoca um

(b)

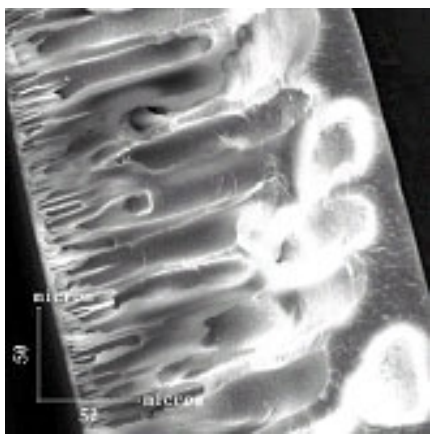

Figura 2. Fotomicrografias das seções transversais de membranas obtidas a partir de solução PAN/NMP com tempo de exposição de 15 s: a) $8 / 92$; b) $15 / 85$. Aumento de $500 x$. 


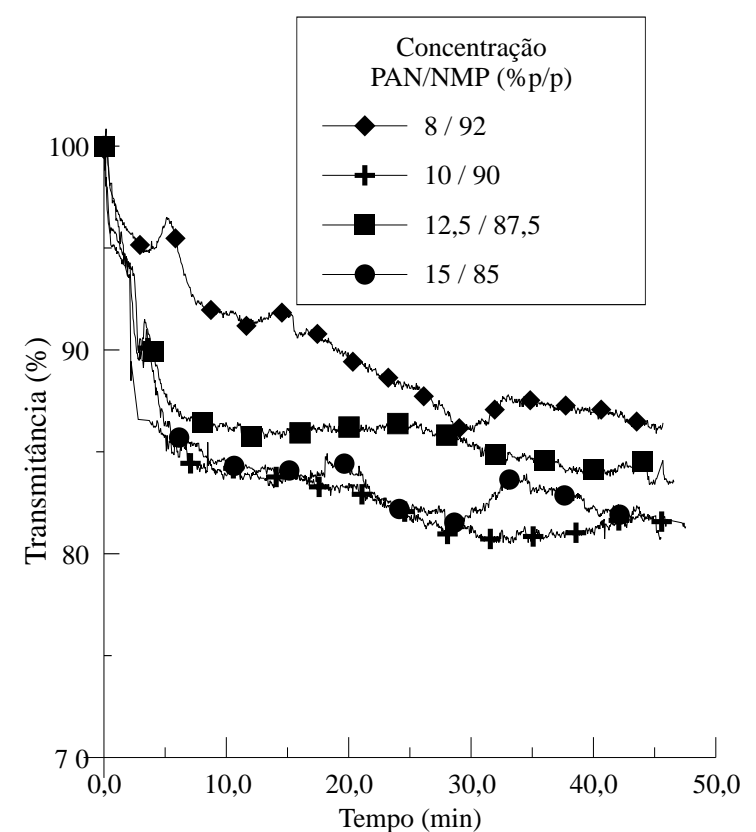

Figura 3. Curvas de cinética de precipitação para as soluções de diferentes concentrações PAN/NMP (tempo de exposição $=30 \mathrm{~s}$ ).

decréscimo na taxa inicial de saída de solvente da solução. Observou-se que a precipitação é instantânea para as condições empregadas no trabalho.

\section{Efeito da concentração de aditivo}

Com o objetivo de alterar a morfologia e/ou a hidrofilicidade de membranas, aditivos tem sido adicionados à solução polimérica. Dentre eles, a poli(vinil pirrolidona) tem como vantagens o fato de ser hidrosolúvel, miscível com vários solventes orgânicos, além das membranas apresentarem menor tendência a formar estrutura digitiforme. Geralmente, a adição de PVP reduz a miscibilidade da solução polimérica com o não solvente, leva a uma aceleração da precipitação e torna o proces- so de separação de fases instantâneo, além de levar a um aumento da porosidade superficial e da interconectividade dos poros nas subcamadas das membranas.

$\mathrm{Na}$ Tabela 1 estão listadas as concentrações empregadas neste trabalho, e na Figura 4 estão ilustradas as micrografias de membranas obtidas a partir de soluções PAN/NMP 12,5/87,5 e PAN/PVP/ NMP [12,5/6,25/81,25].

Segundo Boom ${ }^{[6]}$ para os instantes iniciais da imersão, os dois polímeros (PAN e PVP) podem agir como um só, considerando a difusão entre eles desprezível. Com isto, a solução contendo o aditivo teria maior concentração de polímero, levando a um maior alinhamento dos macroporos obtidos para o sistema polimérico quaternário.

Para os sistemas quaternários estudados também foram realizados ensaios de transmissão de luz durante a precipitação, para as diferentes concentrações de solução polimérica. A Figura 5 mostra as curvas referentes à queda da transmitância de luz através do filme de solução polimérica imerso no banho de não solvente, onde o tempo de leitura dos dados foi de 50 minutos.

A análise desta figura revela uma tendência já esperada, que seria de redução do tempo para o início da precipitação dos sistemas contendo maior concentração de poli(vinil pirrolidona). Também pode ser constatado o mesmo comportamento apresentado pelas curvas de cinética de precipitação das soluções onde a relação polímero base/ aditivo foi a mesma, isto é, as soluções de concentração PAN/PVP/NMP 8/8/84 e 10/10/ 80, da mesma forma que as soluções de concentração $12,5 / 6,25 / 81,25$ e $10 / 5 / 85$. (a)

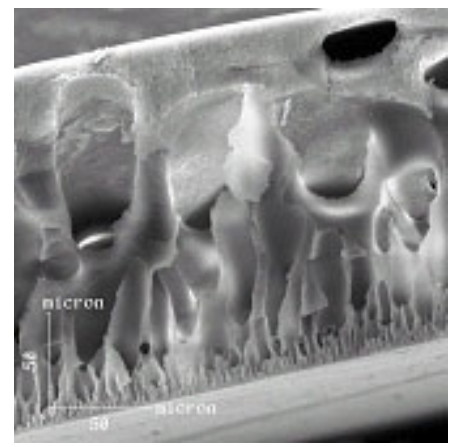

(b)

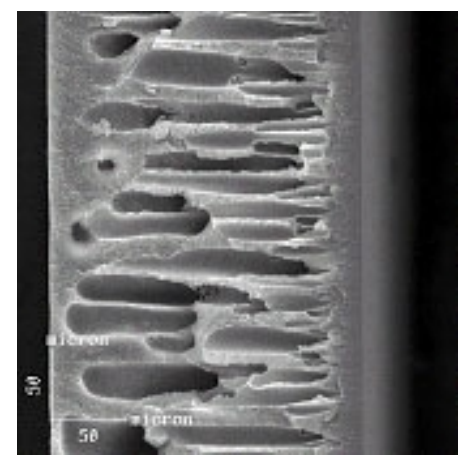

Figura 4. Fotomicrografias das seções transversais de membranas obtidas com tempo de exposição de $30 \mathrm{~s}$ a partir de soluções de concentração a) PAN/NMP 12,5/87,5; b) PAN/PVP/ÁGUA 12,5/6,25/81,25. Aumento de 500x. 


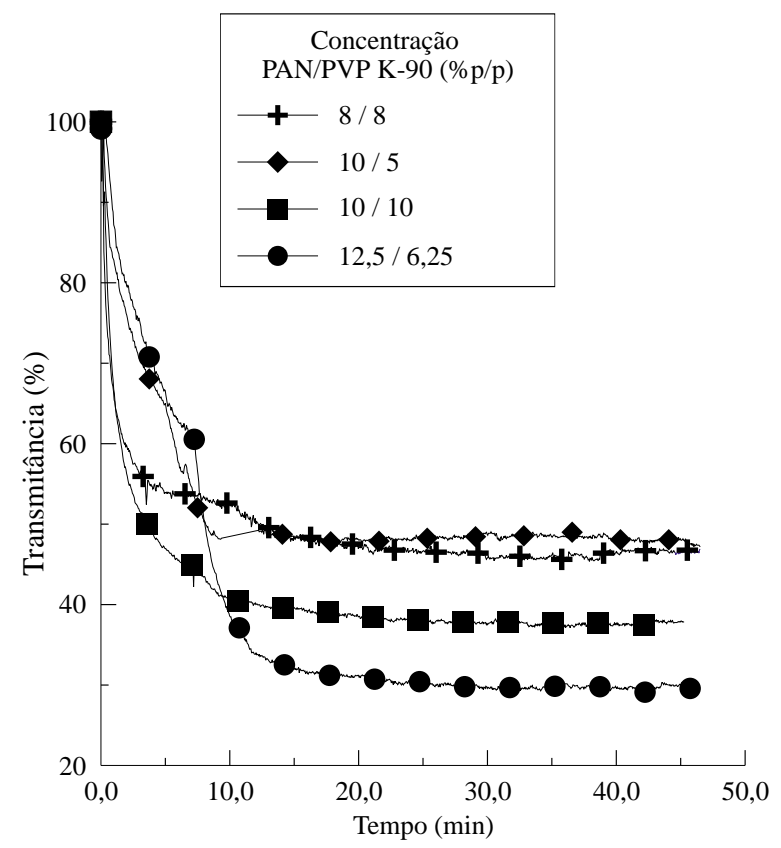

Figura 5. Curvas de cinética de precipitação para as soluções de diferentes concentrações PAN/PVP/NMP (tempo de exposição = 30 s).

\section{Efeito do tratamento térmico da membrana}

Segundo a literatura, na preparação de membranas de PAN para ultrafiltração é necessário tratálas termicamente em água quente, a $90^{\circ} \mathrm{C}$ por 10 min. Este procedimento pode resultar na obtenção de membranas cuja variação máxima na permeabilidade relativa é de $\pm 15 \%{ }^{[7]}$. As membranas porosas de PAN que não foram submetidas ao tratamento térmico antes da secagem em etanol, sofreram colapso dos poros, como é ilustrado na seção transversal da Figura 6a.

Neste estudo variou-se a temperatura do banho de têmpera das membranas antes de submetêlas a secagem. Foram utilizadas as temperaturas de $50^{\circ} \mathrm{C}, 70^{\circ} \mathrm{C}, 80^{\circ} \mathrm{C}$ e $90^{\circ} \mathrm{C}$, por um período de
10 min. Na Figura $6 b$ é ilustrada a fotomicrografia da membrana submetida ao tratamento a $90^{\circ} \mathrm{C}$. Pode ser observado que a membrana submetida ao tratamento térmico é uniforme, com poros interconectados. Este comportamento pode estar relacionado à temperatura de transição vítrea da PAN, em torno de $80-90^{\circ} \mathrm{C}$, devido a mobilidade segmental das cadeias poliméricas.

\section{Caracterização das membranas de PAN por permeação de gás}

As membranas anisotrópicas de PAN, com ou sem a presença de PVP, foram caracterizadas por permeação de nitrogênio, e selecionadas aquelas que apresentaram as maiores permeabilidades, para serem empregadas como suporte na confecção de membranas compostas de PAN/PVA. A Tabela 2 apresenta os valores de permeabilidade, nas membranas obtidas a partir de soluções com diferentes concentrações de PAN e tempo de exposição de $15 \mathrm{~s}$, antes de imergir no banho de precipitação, bem como os valores de permeabilidade nas membranas de PAN obtidas a partir de soluções com diferentes concentrações de aditivo, e tempo de exposição de $30 \mathrm{~s}$, antes da imersão no banho de precipitação.

A partir dos resultados mostrados na tabela 2, selecionou-se as duas condições que apresentaram maiores permeabilidades de nitrogênio (em negrito), para suporte da membrana composta. As membranas porosas de PAN foram cobertas com PVA e caracterizadas por permeação de $\mathrm{N}_{2}$. Entretanto, não foi possível caracterizá-las na pressão de operação do sistema (1,0 a 5,0 bar), devido a baixa permeabilidade das membranas compostas,
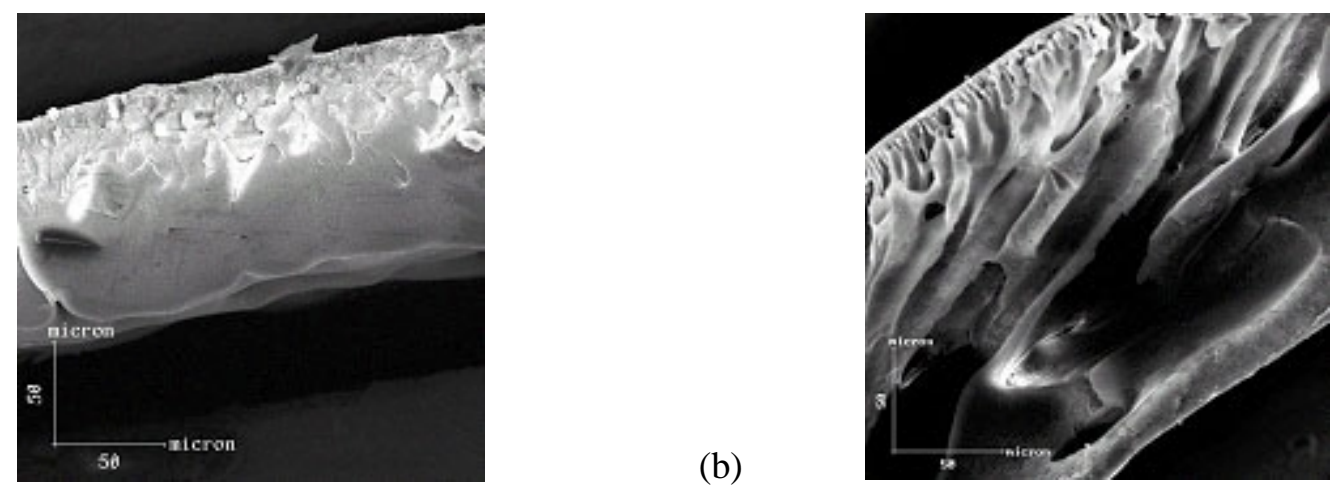

Figura 6. Fotomicrografias das seções transversais de membranas obtidas a partir de solução PAN/NMP 10/90: a) tempo de exposição 60 s e sem tratamento térmico; b) tempo de exposição $30 \mathrm{~s}$ e tratamento térmico a $90{ }^{\circ} \mathrm{C}$. Aumento de $500 \mathrm{x}$. 
Tabela 2. Permeabilidade intrínseca de $\mathrm{N}_{2}$ em membranas anisotrópicas de PAN

\begin{tabular}{cccc}
\hline $\begin{array}{c}\text { PAN/NMP } \\
(\% \mathbf{p} / \mathbf{p})\end{array}$ & $\begin{array}{c}\text { Permeabilidade } \\
\text { Intrínseca } \\
(\mathbf{p} / \mathbf{l})^{\mathbf{a}}\end{array}$ & $\begin{array}{c}\text { PAN/PVP/NMP } \\
(\% \mathbf{p} / \mathbf{p})\end{array}$ & $\begin{array}{c}\text { Permeabilidade } \\
\text { Intrínseca } \\
(\mathbf{p} / \mathbf{l})^{\mathbf{a}}\end{array}$ \\
\hline $8 / 92$ & $\mathrm{~b}$ & $10 / 5 / 85$ & $2,99 \times 10^{-4}$ \\
$10 / 90$ & $7,17 \times 10^{-2}$ & $10 / 10 / 80$ & $8,60 \times 10^{-6}$ \\
$12,5 / 87,5$ & $1,66 \times 10^{-2}$ & $12,5 / 6,25 / 81,75$ & $4,68 \times 10^{-5}$ \\
$15 / 85$ & $1,08 \times 10^{-4}$ & $8 / 8 / 84$ & $3,49 \times 10^{-4}$ \\
\hline
\end{tabular}

a Unidade: $\mathrm{cm}^{3} / \mathrm{cm}^{2}$. $\mathrm{cm} \mathrm{Hg}$. s.

b Não foi possível medir a permeabilidade devido à fragilidade da membrana.

indicando que a pele densa foi suficiente para cobrir os poros superficiais da membrana.

Caracterização das membranas compostas de PAN/ PVA por pervaporação

Neste estudo foi investigada a influência do suporte poroso utilizado sobre os resultados obtidos nos ensaios de pervaporação, através da avaliação dos parâmetros do processo. Na Tabela 3 estão apresentados os resultados de pervaporação de misturas água/etanol para as duas membranas compostas, cobertas com duas camadas de poli(álcool vinílico).

A análise dos resultados mostra que a membrana composta preparada a partir do suporte poroso PAN/PVP/NMP 10/5/85 apresentou menores fluxos permeados e maiores seletividades para o processo, à temperatura de $60^{\circ} \mathrm{C}$ e composição de alimentação água/etanol $\approx 5 / 95$, em detrimento à membrana preparada a partir do suporte PAN/NMP 12,5/87,5. Comparando o suporte que apresentou melhor resultado, com a membrana comercial da GFT, pode ser observado que o comercial apresentou melhor desempenho na separação, porém fluxo permeado menor.

Os resultados obtidos parecem indicar que o suporte de poliacrilonitrila influenciou a capacidade seletiva da membrana composta, atuando conjuntamente com a pele densa constituída do polímero hidrofílico [poli(álcool vinílico)] no processo seletivo.

\section{Conclusão}

No estudo dos parâmetros que afetam a morfologia das membranas porosas pode ser observado que, o aumento da concentração de PAN na solução polimérica favoreceu maior alinhamento dos macroporos ao longo da seção transversal das membranas. Por outro lado, a presença de PVP na solução polimérica minimizou a formação de macrovazios na membrana. Além disso, com o aumento da concentração do aditivo há redução do tempo do início de formação da membrana, ao ser imersa não solvente.

As menores permeabilidades gasosas em suportes obtidos a partir de sistemas quaternários PAN/PVP/NMP/ÁGUA, quando comparados aos obtidos sem o aditivo, podem justificar os resultados obtidos em pervaporação. A membrana composta preparada a partir do suporte $\mathrm{PAN} / \mathrm{PVP} / \mathrm{NMP}$ $10 / 5 / 85$ apresentou menor fluxo permeado e maior seletividade, à temperatura de $60^{\circ} \mathrm{C}$ e composição de alimentação água/etanol $\approx 5 / 95$, indicando que o suporte pode desempenhar papel importante no processo de pervaporação.

\section{Agradecimento}

À FAPERJ pelo suporte financeiro ao projeto e a bolsa de iniciação científica de Rodrigo Cruz Lavall.

Tabela 3. Testes de pervaporação de misturas água/etanol para os dois suportes porosos selecionados: PAN/NMP 12,5/87,5 (suporte A), e PAN/PVP/NMP 10/5/85 (suporte B).

\begin{tabular}{cccccc}
\hline Teste & $\begin{array}{c}\text { Temperatura } \\
\left({ }^{\circ} \mathbf{C}\right)\end{array}$ & $\begin{array}{c}\text { Alimentação } \\
(\% \text { água })\end{array}$ & $\begin{array}{c}\text { Permeado } \\
(\% \text { água })\end{array}$ & $\begin{array}{c}\text { Fluxo Permeado } \\
\left(\mathbf{K g} / \mathbf{h} . \mathbf{m}^{2}\right)\end{array}$ & $\begin{array}{c}\text { Seletividade } \\
\left(\boldsymbol{\alpha}_{\text {H2O/toH }}\right)\end{array}$ \\
\hline $1^{\mathrm{a}}$ & 50 & 20,51 & 73,86 & 2,10 & 11,0 \\
$2^{\mathrm{b}}$ & 50 & 15,64 & 83,76 & $4,12 \times 10^{-1}$ & 27,8 \\
$3^{\mathrm{c}}$ & 50 & 15,46 & 94,81 & $1,24 \times 10^{-1}$ & 99,9 \\
$4^{\mathrm{a}}$ & 60 & 6,07 & 59,90 & $8,07 \times 10^{-1}$ & 23,1 \\
$5^{\mathrm{b}}$ & 60 & 5,26 & 82,55 & $1,51 \times 10^{-1}$ & 85,3 \\
\hline
\end{tabular}

a suporte poroso PAN/NMP 12,5/87,5

${ }^{\mathrm{b}}$ suporte poroso PAN/PVP/NMP $10 / 5 / 85$

${ }^{\mathrm{c}}$ membrana comercial composta PVA/PAN (GFT n ${ }^{\circ}$ de catálogo 1000) 


\section{Referências Bibliográficas}

1. Nobrega, R.; Garcia, M.E.F. e Habert,A .C., Polímeros: Ciência e Tecnologia, 1, 18, (1991).

2. Huang, R.Y.M., Membrane Science and Technology Series.1.Pervaporation Membrane Separation Processes, Elsevier, Amsterdam, 1a ed., (1991).

3. Kim, H.J.; Jo, W.H. e Kang,Y.S., J. Appl. Polym. Sci., 57, 63, (1995).

4. Néel, J., Pervaporation, Lavoisier Tec \& Doc, Paris, $1^{\text {a }}$ ed., (1996).
5. Cabral, L.M.C., Estudo Morfológico de Membranas Sintetizadas a Partir da Mistura Poli(étersulfona)/ Polivinilpirrolidona, Tese de Doutorado, COPPE/UFRJ, Rio de Janeiro, RJ,Brasil, (1994).

6. Boom, R.M., Membrane Formation by Immersion Precipitation: The Role of a Polymeric Additive, University of Twente, Enschede, The Netherlands, (1992).

7. Hicke, H-G.; Bohme, P.; Becker, M.; Shulze, H. e Ulbricht, M., J. Appl. Polym. Sci., 60, 1147, (1996). 